\title{
Chemical proprieties of the iron-quinone complex in mutated reaction centers of $R \mathbf{b}$. sphaeroides
}

\author{
Agnieszka Hałas • Valerie Derrien • Pierre Sebban • \\ Krzysztof Matlak • Józef Korecki • Jerzy Kruk • \\ Květoslava Burda
}

Received: 1 September 2011 / Accepted: 27 October 2011 / Published online: 16 November 2011

(C) The Author(s) 2011. This article is published with open access at Springerlink.com

\begin{abstract}
We investigated type II bacterial photosynthetic reaction centers, which contain a quinone - iron complex $\left(\mathrm{Q}_{\mathrm{A}}-\mathrm{Fe}-\mathrm{Q}_{\mathrm{B}}\right)$ on their acceptor side. Under physiological conditions it was observed mainly in a reduced high spin state but its low spin ferrous states were also observed. Therefore, it was suggested that it might regulate the dynamical properties of the iron-quinone complex and the protonation and deprotonation events in its neighbourhood. In order to get insight into the molecular mechanism of the NHFe low spin state formation, we preformed Mössbauer studies of a wild type of $R b$. sphaeroides and its two mutated forms. Our Mössbauer measurements show that the hydrophobicity of the $\mathrm{Q}_{\mathrm{A}}$ binding site can be crucial for stabilization of the high spin ferrous state of NHFe.
\end{abstract}

Keywords Photosynthetic reaction center • Non-heme iron

International Conference on the Application of the Mössbauer Effect

\footnotetext{
A. Hałas · K. Burda

Faculty of Physics and Computer Science, Department of Medical Physics and Biophysics, AGH University, Kraków, Poland

V. Derrien · P. Sebban

Laboratoire de Chimie Physique, University of Paris XI, Orsay, France

K. Matlak · J. Korecki

Faculty of Physics and Computer Science, Department of Solid State Physics, AGH University, Kraków, Poland

J. Kruk

Faculty of Biochemistry, Biophysics and Biotechnology, Jagiellonian University,

Kraków, Poland

K. Burda $(\varangle)$

Faculty of Physics and Computer Science, AGH University, al. Mickiewicza 30,

30-059 Kraków, Poland

e-mail: kvetoslava.burda@fis.agh.edu.pl
} 
Abbreviations

$\begin{array}{ll}\text { Bacterial reaction center } & \mathrm{BRC} \\ \text { Rhodobacter sphaeroides } & R b \text {. sphaeroides } \\ \text { Rhodospirillum rubrum } & R p \text {. rubrum } \\ \text { Quinone-iron complex } & \mathrm{Q}_{\mathrm{A}-\mathrm{Fe}-\mathrm{Q}_{\mathrm{B}}} \\ \text { Non-heme iron } & \mathrm{NHFe} \\ \text { Electron transfer } & \mathrm{ET} \\ \text { Ubiquinone } & \mathrm{UQ} \\ \text { Wild type } & \mathrm{WT} \\ \text { Isomer shift } & \mathrm{IS} \\ \text { Quadrupole splitting } & \mathrm{QS}\end{array}$

\section{Introduction}

The bacterial photosynthetic reaction center (BRC) is a membrane protein complex, which converts light energy into chemical free energy. BRC of Rhodobacter sphaeroides (Rb.sphaeroides), which belongs to purple bacteria, is considered as a model system to study the dynamical and structural proprieties of the photosynthetic reaction centers of type II. Each BRC is composed of three protein subunits L, M and $\mathrm{H}$. The $\mathrm{L}$ and $\mathrm{M}$ proteins are connected on the acceptor side by the non-heme iron $(\mathrm{NHFe})$ situated between the primary and secondary ubiquinone acceptor $\mathrm{Q}_{\mathrm{A}}$ and $\mathrm{Q}_{\mathrm{B}}$, respectively. The ubiquinone is tightly bound to the $\mathrm{Q}_{\mathrm{A}}$ site contrary to the one at the $\mathrm{Q}_{\mathrm{B}}$ site. The $\mathrm{Q}_{\mathrm{A}}$ ubiquinone, bound to the $\mathrm{M}$ subunit, is in a hydrophobic area whereas the $\mathrm{Q}_{\mathrm{B}}$ ubiquinone, bound to the $\mathrm{L}$ subunit, is surrounded by charged and polar residues. The molecular mechanisms of the electron transfer between $\mathrm{Q}_{\mathrm{A}}$ and $\mathrm{Q}_{\mathrm{B}}$ ubiquinones have been a subject of challenging studies but the role of the $\mathrm{NHFe}$, which is a very conservative component of RCs of the type II, in this process is still unknown [1,2]. Especially the role of NHFe in stabilization of the $\mathrm{Q}_{A}$ and $\mathrm{Q}_{B}$ binding sites and in the primary electron transfer (ET) is not clear. A change of the $\mathrm{NHFe}$ valence state has never been detected in any system of type II [3]. But mixed spin states (low and high spin state) were observed in BRCs of $R b$. sphaeroides and of Rp. rubrum [4,5] and an exclusively low spin state in photosystem II of algae PSI ${ }^{-}$ mutant $[6,7]$. We focused on studies of the NHFe valence and spin states in BRCs isolated form a wild type (WT) and two mutants of Rb. sphaeroides (see Fig. 1) [8, 9]. The double mutant, called later in this paper AA, has two point mutations near the $\mathrm{Q}_{\mathrm{B}}$ acidic cluster: (L212Glu/L213Asp -> Ala/Ala). The triple mutant, called AATyr, has additionally a point mutation near the $\mathrm{Q}_{\mathrm{A}}$ binding site (M249Ala-> Tyr).

In our studies we applied Mössbauer spectroscopy to investigate the valence and spin state of the probing atom i.e. the isotope ${ }^{57} \mathrm{Fe}$.

\section{Materials and methods}

The HIS tagged cells of Rb.sphaeroides (native and harbouring mutations) were grown in the medium deprived of natural iron and enriched with an iron isotope ${ }^{57} \mathrm{Fe}$. The growing conditions and the BRC purification have previously been described 


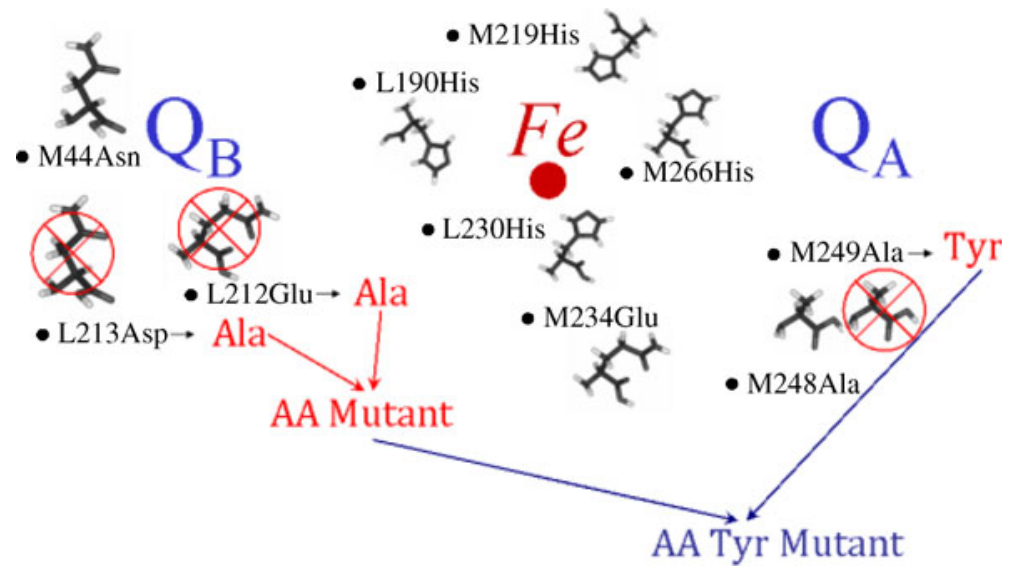

Fig. 1 The arrangement of amino acids at the proximity of the iron-quinone complex $\left(\mathrm{Q}_{A}-\mathrm{Fe}-\mathrm{Q}_{B}\right)$ in Rb.sphaeroides

Fig. 2 Mössbauer spectra of WT (a), AA (b) and AATyr (c) BRC isolated from $R b$. sphaeroides. The solid lines represent fits assuming symmetrical lorentzians. Different components are indicated by various colors. The spectra were measured at $85 \mathrm{~K}$
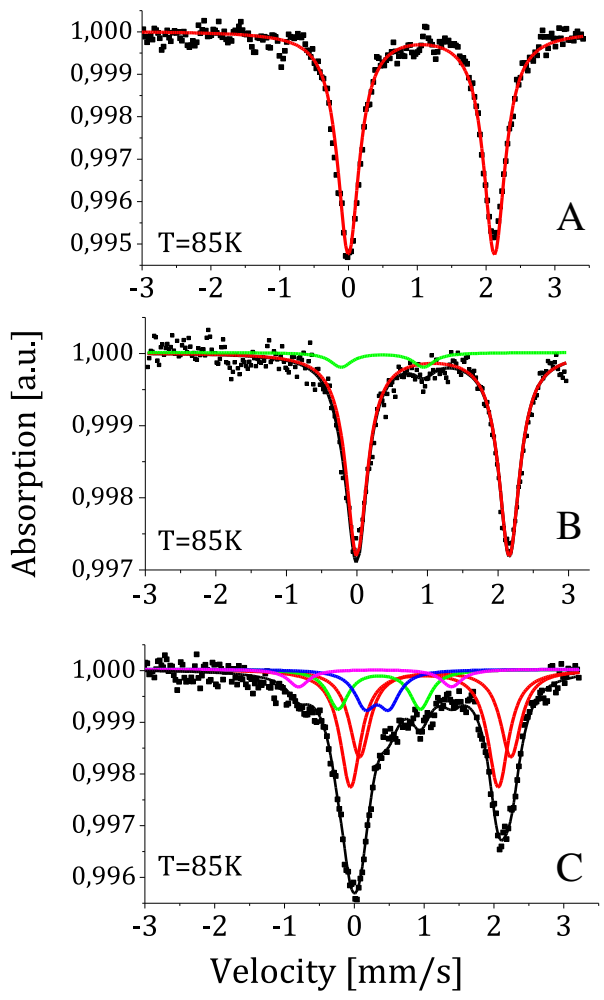

in [9]. We used $900 \mathrm{nmol}, 800 \mathrm{nmol}$ and $1400 \mathrm{nmol}$ in the WT, AA and AATyr BRCs, respectively. No differences were observed in the absorption spectra of the WT BRCs and its two mutated types (data not presented). The Mössbauer spectra were recorded in a home made cryostat using $50 \mathrm{mCi}{ }^{57} \mathrm{Co} / \mathrm{Rh}$ and a proportional 
Table 1 The hyperfine parameters of NHFe fitted to the Mössbauer spectra of WT, AA and AATyr BRCs

\begin{tabular}{|c|c|c|c|c|c|}
\hline Hyperfine parameters & Component 1 & Component 2 & Component 3 & Component 4 & Component 5 \\
\hline \multicolumn{6}{|l|}{ WT } \\
\hline IS $[\mathrm{mm} / \mathrm{s}]$ & $1,06 \pm 0,01$ & & & & \\
\hline $\mathrm{QS}[\mathrm{mm} / \mathrm{s}]$ & $2,12 \pm 0,01$ & & & & \\
\hline $\mathrm{A}[\%]$ & $100 \pm 2$ & & & & \\
\hline \multicolumn{6}{|l|}{ AA } \\
\hline IS [mm/s] & $1,08 \pm 0,01$ & & $0,36 \pm 0,10$ & & \\
\hline $\mathrm{QS}[\mathrm{mm} / \mathrm{s}]$ & $2,16 \pm 0,01$ & & $1,17 \pm 0,20$ & & \\
\hline $\mathrm{A}[\%]$ & $93 \pm 2$ & & $7 \pm 1$ & & \\
\hline \multicolumn{6}{|l|}{ AA Tyr } \\
\hline IS [mm/s] & $1,15 \pm 0,03$ & $0,99 \pm 0,03$ & $0,25 \pm 0,04$ & $0,13 \pm 0,05$ & $0,17 \pm 0,10$ \\
\hline $\mathrm{QS}[\mathrm{mm} / \mathrm{s}]$ & $2,12 \pm 0,02$ & $2,10 \pm 0,03$ & $0,98 \pm 0,10$ & $1,9 \pm 0,1$ & $0,44 \pm 0,10$ \\
\hline $\mathrm{A}[\%]$ & $38 \pm 7$ & $33 \pm 6$ & $10 \pm 2$ & $9 \pm 1$ & $10 \pm 2$ \\
\hline
\end{tabular}

IS: isomeric shift, QS: quadrupole splitting. A: contribution in the spectrum. The line width in all cases was $0.18 \pm 0.01 \mathrm{~mm} / \mathrm{s}$

counter to detect the radiation. The temperature stabilization was within $0.1 \mathrm{~K}$. The isomer shifts are given vs. metallic $\mathrm{Fe}$ at room temperature. The recorded spectra were fitted using a Recoil program [10].

\section{Results and discussion}

In Fig. 2 we present Mössbauer spectra for BRCs of high purity obtained from wild type, AA and AATyr mutant of Rb. sphaeroides.

The hyperfine parameters of NHFe obtained from theoretical fits are given in Table 1.

The spectrum of WT BRCs is composed of a single doublet with hyperfine parameters characteristic for a high spin $\mathrm{Fe}^{2+}$ state $[4,11]$. In the case of the AA mutant, the spectrum contains component of the high spin reduced state of the iron atom and a small contribution of a component, whose hyperfine parameters are more similar to those observed usually in the case of the reduced low spin state of the heme-iron in cytochromes [4, 12]. The AATyr spectrum is very different from those detected for WT and AA mutant BRCs. It requires five components to get a fit of good quality. The two components having isomer shift (IS) of about $1 \mathrm{~mm} / \mathrm{s}$ are typical for a high spin ferrous state. Our estimation of this spectrum with a distribution of a quadrupole splitting (QS) showed that we can deconvolute this part of the spectrum using two sub-spectra. Component with IS $=0.13 \mathrm{~mm} / \mathrm{s}$ and $\mathrm{QS}=1.9 \mathrm{~mm} / \mathrm{s}$ is more typical for iron in octahedral coordination, when one of the perpendicular ligands has a different character than the others. It is very often observed for heme - iron ligated with $\mathrm{O}_{2}$ [13] but in our BRCs we have sixcoordinated non-heme iron, what means that at least one of its ligands had to be modified in comparison to the state when NHFe occurs in a high $\mathrm{Fe}^{2+}$ state. The sub-spectrum with $\mathrm{QS} \approx 1.0 \mathrm{~mm} / \mathrm{s}$ is most probably related to the same NHFe state which is observed in the AA mutant but having a higher symmetry of the binding site. The sub-spectrum with the lowest quadrupole is related to the low spin ferrous state 
of NHFe. Its hyperfine parameters do not change with the increasing temperature. A similar $\mathrm{NHFe}$ state was already observed in other photosynthetic systems of type II [4-7]. To understand the complexity of the AATyr spectra we performed measurements of the amount of ubiquinone binding at the $\mathrm{Q}_{\mathrm{B}}$ site per reaction center using HPLC [14]. The ratio of ubiquinone $\mathrm{Q}_{B}$ per reaction center is $0.24,0.77$ for WT and AA, respectively, and no ubiquinone at this site was detected for AATyr BRCs. From those results, it turns out that the occupation of the $\mathrm{Q}_{\mathrm{B}}$ site by UQ is not directly related to the state of NHFe. It was already shown in the reconstitution experiments, when independently of the amount of bound $\mathrm{UQ}$ at the $\mathrm{Q}_{\mathrm{B}}$ site, only high spin ferrous state of NHFe was observed [11]. Therefore, we suggest that the presence of various states of NHFe in the case of AATyr BRCs is caused by the modification of the hydrophobicity in the vicinity of the $\mathrm{Q}_{\mathrm{A}}$ binding site, whose differences between the double AA and triple AATyr mutant are confirmed (see Fig. 1).

\section{Conclusion}

The presented results suggest that the spin state of NHFe is not sensitive to the presence of the ubiquionone at the $\mathrm{Q}_{\mathrm{B}}$ site but it is easily affected by the hydrogen network in the vicinity of the $\mathrm{Q}_{\mathrm{A}}$ binding site. Especially, the hydrophobic character of the $\mathrm{Q}_{\mathrm{A}}$ binding site is very important for the stabilization of the high spin ferrous state of NHFe, having been proved by the obtained Mössbauer spectra for the AATyr mutant in which M249Ala was substituted into a hydrophilic amino acid, tyrosine. The planned temperature dependent measurements will show if this modification of the acceptor site near the $\mathrm{Q}_{\mathrm{A}}$ binding site may also influence the local flexibility of NHFe.

Acknowledgements This work was supported partially by grant No N N302 195035 (2008-2011) from Polish Ministry of Science and Higher Education. The groups cooperate within the BIONAN project. Project operated within the Foundation for Polish Science MPD Programme co-financed by the EU European Regional Development Fund. (A.H)

Open Access This article is distributed under the terms of the Creative Commons Attribution Noncommercial License which permits any noncommercial use, distribution, and reproduction in any medium, provided the original author(s) and source are credited.

\section{References}

1. Kleinfeld, D., Okamura, M.Y., Feher, G.: Electron-transfer kinetics in photosynthethic reaction centers cooled to cryogenic temperatures in the charge-separated state: evidence for lightinduced structural changes. Biochemistry 23, 5780-5786 (1984)

2. Burda, K: Dynamics of electron transfer in photosystem II. Cell Biochem. Biophys. 47(2), 271284 (2007)

3. Hermes, S., Bremm, O., Garczarek, F., Derrien, V., Liebisch, P., Loja, P., Sebban, P., Gerwert, K., Haumann, M.: A time-resolved iron-specific x-ray absorption experiment yields no evidence for an $\mathrm{Fe}^{2+}$ to $\mathrm{Fe}^{3+}$ transition during $\mathrm{Q}_{\mathrm{A}}^{-}$to $\mathrm{Q}_{\mathrm{B}}$ electron transfer in the photosynthetic reaction center. Biochemistry 45(2), 353-359 (2006)

4. Orzechowska, A., Lipinska, M., Fiedor, J., Chumakov, A., Zajac, M., Slezak, T., Matlak, K., Strzalka, K., Korecki, J., Fiedor, L., Burda, K.: Coupling of collective motions of the protein 
matrix to vibrations of the non-heme iron in bacterial photosynthetic reaction centers. Biochim. Biophys. Acta. Bioenerg. 1797, 1696-1704 (2010)

5. Lipinska, M., Orzechowska, A., Fiedor, J., Chumakov, A.I., Slezak, T., Zajac,M., Matlak, K., Korecki, J., Hałas, A., Strzalka, K., Fiedor, L., Burda, K.: Influence of $\mathrm{Cd}^{2+}$ on the spin state of non-heme iron and on protein local motions in reactions centers from purple photosynthetic bacterium Rhodospirilium rubrum. J. Phys.: Conf. Ser. 217, 012021(ICAME 2009) 135 (2010)

6. Burda, K., Kruk, J., Borgstädt, R., Stanek, J., Strzalka, K, Schmid, G.H., Kruse, O.: Low spin ferrous state of the non-heme iron in a Chlamydomonas reinhardtii PSI- mutant. FEBS Lett. 535, 159-165 (2003)

7. Burda, K., Kruk, J., Strzałka, K., Stanek, J., Schmid G.H., Kruse, O.: Moessbauer studies of $\mathrm{Cu}(\mathrm{II})$ ions interaction with the non-heme iron and cytochrome b559 in a Chlamydomonas reinhardtii PSI minus mutant. Acta Physica Polonica A 109, 237-247 (2006)

8. Tandori, J., Baciou, L., Alexov, E., Maroti, P., Schiffer, M., Hanson, D.K., Sebban, P.: Revealing the involvment of extended hydrogen-bond networks in the cooperative function between distant sites in bacterial centers. J. Biol. Chem. 276, 45513-45515 (2001)

9. Sacquin-Mora, S., Sebban, P., Derrien, V., Frick, B., Lavery, R., Alba-Simionesco, C.: Probing the flexibility of the bacterial reaction center: the wild-type protein is more rigid than two sitespecific mutants. Biochemistry 46, 14960-14968 (2007)

10. Rancourt, D.G., Ping, J.-Y.: Voigt-based methods for arbitrary-shape static hyperfine parameter distributions in Mössbauer spectroscopy. Nucl. Instr. Methods B 58, 85-97 (1991)

11. Debus, R.J., Feher, G., Okamura, M.Y.: Iron-depleted reaction centers from Rhodopseudomonas sphaeroides R-26. 1: characterization and reconstitution with $\mathrm{Fe} 2+$, $\mathrm{Mn} 2+, \mathrm{Co} 2+, \mathrm{Ni} 2+, \mathrm{Cu} 2+$, and Zn2+. Biochemistry 25, 2276-2287 (1986)

12. Garbers, A., Reifarth, F., Kurreck, J., Renger, G., Parak, F.: Correlation between protein flexibility and electron transfer from $\mathrm{Q}_{\mathrm{A}}{ }^{-*}$ to $\mathrm{Q}_{\mathrm{B}}$ in PSII membrane fragments from spinach. Biochemistry 37, 11399-11404 (1998)

13. Lang, G., Marshall, W.: Mössbauer effect in some hemoglobin compounds. Proc. Phys. Soc. 87, 3-34 (1966)

14. Kruk, J., Trebst, A.: Plastoquinol as a singlet oxygen scavenger in photosystem II. BBA Bioenergetics 1777, 154-162 (2008) 